\title{
A five year audit of the role of parathyroid hormone assays and thallium-technetium isotope subtraction scanning in the preoperative investigation of primary hyperparathyroidism
}

\author{
Jeremy I. Livingstone*, Marisol Tellez, Michael Burke, Peter J. Ashby† and \\ Michael G. Rinsler
}

\author{
Departments of ${ }^{1}$ Surgery, ${ }^{2}$ Radioisotopes and ${ }^{3}$ Clinical Chemistry, Northwick Park Hospital, Watford \\ Road, Harrow, Middlesex HAI 3UJ, UK.
}

\begin{abstract}
Summary: An audit has been performed of the value of parathyroid hormone assays and thallium-technetium isotope scanning in the pre-operative investigation of 67 hypercalcaemic patients referred for surgery over a 5 year period. Parathyroid hormone assay by region-specific technique was found to have a diagnostic sensitivity of $75 \%(n=52)$ whilst the more recent assay for the intact molecule was $97 \%$ sensitive $(n=34)$. Thallium-technetium isotope scanning was only $64 \%$ sensitive overall $(n=59)$, due in part to the small size of adenomata now being referred for surgery. This study confirms the role of the intact parathyroid hormone assay but questions that of thallium-technetium isotope scanning in standard protocols of investigation for hypercalcaemia.
\end{abstract}

\section{Introduction}

The difficulties facing the clinician in primary hyperparathyroidism are those of confirmation of the diagnosis and localization of the underlying lesion at operation. Early assays of parathyroid hormone (PTH) by region-specific techniques for the amino or carboxy terminal or mid-molecule fragments were unreliable due to the presence of circulating degradation products causing overlap with the normal range. ${ }^{1,2}$ The more recent two-site immunoradiometric assay for the intact molecule has appeared more promising. ${ }^{1,3,4}$ Thallium-technetium subtraction scintigraphy has emerged as arguably the best imaging technique to confirm the diagnosis and to aid operative localization. ${ }^{5-8}$

The aim of this review was to evaluate the role of parathyroid hormone assays and thallium-technetium isotope scanning as part of a standard protocol of investigation in patients with hypercalcaemia, prospectively applied over a 5 year period.

Present addresses: *Watford General Hospital, Vicarage Road, Watford, UK.

†Western General Hospital, Crewe Road, Edinburgh, UK.

Correspondence: M. Burke, M.S., F.R.C.S., Department of Surgery.

Accepted: 25 June 1991

\section{Patients and methods}

Sixty-seven consecutive patients referred to the surgical unit between 1983 and 1988 were studied, all of whom had been investigated by a standard clinical and biochemical protocol prior to referral. None of the patients had previously undergone any parathyroid surgery. The average age at operation was 57 years (range 22-84 years) with a preponderance of 53 female patients to 14 male. In the early part of the study period, parathyroid hormone assay was performed by region specific technique. ${ }^{2}$ Subsequently, when a commercial radioimmunometric assay for the intact molecule became available (Allegro intact PTH assay kit), ${ }^{3}$ this was added to the investigation protocol. The assay results were re-interpreted for predictive value by one observer at the time of this review.

Once a clinical and biochemical diagnosis of hyperparathyroidism had been reached, isotope subtraction scanning was performed according to standard methods described by Young et al. in 1983. ${ }^{5}$ Practical contra-indications to scanning were known concomitant thyroid disease (2 patients), patient frailty or abnormal physical characteristics (5 patients), or pregnancy (1 patient). All the scans were re-examined at the time of this review by one observer.

Surgery was performed by 1 of 2 experienced 
endocrine surgeons via a transverse cervical incision with mobilization of all 4 poles of the thyroid gland and with frozen section histology facilities available. Histological analysis was performed on all resected specimens after they had been cleaned and weighed.

\section{Results}

Fifty-eight patients $(86.5 \%)$ were found at operations to have a solitary adenoma whilst $5(7.6 \%)$ had hyperplasia of at least 2 glands. One patient had a double adenoma. There were no carcinomas. In $3(4.5 \%)$ patients, no abnormal parathyroid tissue was found. These figures correlate well with those of previous studies. ${ }^{9,10}$ The average mass of resected adenomata was $1.01 \mathrm{~g}$ (range 0.11-4.0 g).

The results of parathyroid hormone assay are summarized in Table I. Region-specific assay was performed in 52 of the 67 patients. A result regarded as true positive was obtained in 39 patients of whom 37 were found to have adenomata and 2 hyperplastic glands. In 4 patients with adenomata, the region-specific assay results were against the diagnosis, whilst in a further 9 patients, the result was borderline or equivocal. Of these 9 patients, 7 were subsequently found to have an adenoma. Thus, the overall diagnostic sensitivity for the region-specific assays was $75 \%$. The intact parathyroid hormone assay was performed on 34 patients. A result regarded as true positive was returned in 31 patients of whom 29 were found at surgery to have a solitary adenoma and 2 hyperplastic glands. In two patients with normal intact assay results, no abnormal parathyroid tissue was found. The only error in the intact assay group was a case of hyperplasia in a 48 year old male with a serum calcium of $2.62 \mathrm{~mm} / 1$, who returned a persistently normal result. Thus the overall diagnostic sensitivity for the intact assay was $\mathbf{9 7 \%}$.

In 20 patients with adenomata and 4 with hyperplasia, it was possible to perform both types of assay. The intact assay was correctly predictive in all cases whilst in 5 patients with adenomata, the region-specific assay returned an equivocal result including in one patient with a large lesion of $1.44 \mathrm{~g}$.

The results of thallium-technetium subtraction scanning are summarized in Table II. Fifty-nine patients were scanned; 38 scans were concordant with the surgical findings; 36 scans accurately predicted the side and polarity of 31 adenomata, the correct side only of 3 further adenomata and 2 cases of hyperplasia. In 2 patients with negative scans, no abnormal parathyroid tissue was found at operation. Twenty-one scans were discordant with the surgical findings; 20 scans were falsely negative in 17 patients with an adenoma and 3 with
Table I Results of parathyroid hormone assay

No. of
patients $\quad$ Surgical pathology

(A) Region-specific assay

\begin{tabular}{|c|c|c|}
\hline True positive & 39 & $\begin{array}{l}36 \text { adenomata, } 2 \text { hyperplasia } \\
1 \text { double adenoma }\end{array}$ \\
\hline False negative & 4 & 4 adenomata \\
\hline Equivocal & 9 & $\begin{array}{l}7 \text { adenomata } \\
2 \text { negative explorations }\end{array}$ \\
\hline
\end{tabular}

Total 52

(B) Intact assay

True positive

True negative

False negative

Total

2 No abnormal glands

1 Hyperplasia

34

hyperplastic glands. The false negative scans either failed to show any lesion at all or else suggested a lesion in a site incompatible with that subsequently demonstrated at operation. In one patient in whom the scan predicted an adenoma, only normal parathyroid tissue was found at operation. The diagnostic sensitivity of scanning was therefore $59 \%$ for complete concordance with the surgical findings and $64 \%$ including those scans in whicho the correct side of the lesion was predicted.

Of 17 adenomata missed by scintigraphy, 8 were located in relation to the upper left pole of the thyroid in contrast with 3 and 4 in each of the inferior poles and 2 on the right upper pole. The average mass of adenomata correctly localized was $1.26 \mathrm{~g}$, a significant difference from the average mass of the missed lesions at $0.49 \mathrm{~g}(P<0.002$, Wilcoxon rank test).

\section{Discussion}

Our experience of the intact parathyroid hormone assay parallels that of other groups in that it has a high diagnostic sensitivity and is straightforward and robust in routine use. ${ }^{3,11}$ In many patients this obviates the need for more complex inpatient investigation.

We have been disappointed with the outcome of thallium-technetium isotope scanning. Although the technique is known to be less reliable in patients with thyroid disease and hyperplastic glands, the main determinant of accuracy seems to be the size of the lesion. Certainly, lesions of less than $0.5 \mathrm{~g}$ are difficult to detect ${ }^{6,7,12}$ and indeed the average mass in our discordant scan group was $0.49 \mathrm{~g}$. The overall average mass of an adenoma in our series was $1.01 \mathrm{~g}$. Whilst comparison between reviews may be unreliable, most centres quoting a sensi- 
Table II Summary of scintigraphy

\begin{tabular}{|c|c|c|}
\hline & $\begin{array}{c}\text { No. of } \\
\text { patients }\end{array}$ & Surgical pathology \\
\hline \multicolumn{3}{|c|}{ (A) Concordant scans } \\
\hline True positive & 36 & $\begin{array}{l}31 \text { adenomata (side and } \\
\text { polarity) } \\
3 \text { adenomata (side only) } \\
2 \text { hyperplasia }\end{array}$ \\
\hline True negative & 2 & No abnormal glands \\
\hline Total & 38 & \\
\hline \multicolumn{3}{|c|}{ (B) Discordant scans } \\
\hline False negative & 20 & 17 adenomata, 3 hyperplasia \\
\hline False positive & 1 & Lymph node \\
\hline Total & 21 & \\
\hline
\end{tabular}

tivity for scanning of $75-80 \%$ are excising lesions with an average mass of the order of $1.3-1.5 \mathrm{~g}^{7,13,14}$ and this may in part explain our poor results in comparison.

During the time of the study it was noted that the adenomata being removed were becoming smaller (Figure 1). This has not been reported elsewhere but is likely to be the result of increased detection of subclinical cases by multi-channel biochemical screening, improved assessment by endocrine physicians including use of the intact hormone assay, increased awareness of the importance of prompt treatment of hypercalcaemia and increased confidence in the reliability and safety of surgery. From 1986 in particular, the average mass of an adenoma we have resected has been of the order of $0.6 \mathrm{~g}$ and thus at the limits of detection by scintigraphy. By contrast, the experienced surgeon is likely to find the underlying pathology in $95 \%$ of

\section{References}

1. Curley, I.R., Wheeler, M.H., Aston, J.P. et al. Studies in patients with hyperparathyroidism using a new two-site immunochemiluminometric assay for circulating intact (184) parathyroid hormone. Surgery 1987, 102: 926-931.

2. Ashby, J.P. \& Thakkar, H. Diagnostic limitations of regionspecific parathyroid hormone assays in the investigation of hypercalcaemia. Ann Clin Biochem 1988, 25: 275-279.

3. Newman, D.J. \& Ashby, J.P. Clinical and laboratory evaluation of a two-site immunoradiometric assay for intact parathyroid hormone. Ann Clin Biochem 1988, 25: 654-660.

4. Lindall, A.W., Elting, J., Ells, J. et al. Estimation of biologically active intact parathyroid hormone in normal and hyperparathyroid sera by sequential $\mathrm{N}$-terminal immunoextraction and mid-region radioimmunoassay. $J$ Clin Endocrinol Metab 1983, 57: 1007-1014.

5. Young, A.E., Gaunt, J.I., Croft, D.N. et al. Localisation of parathyroid adenomas by thallium-201 and technetium- $99 \mathrm{~m}$ subtraction scanning. Br Med J 1983, 286: 1384-1386.

6. Okerland, M.D., Sheldon, K., Corpuz, S. et al. A new method with high sensitivity and specificity for localisation of abnormal parathyroid glands. Ann Surg 1984, 200: 381-388.

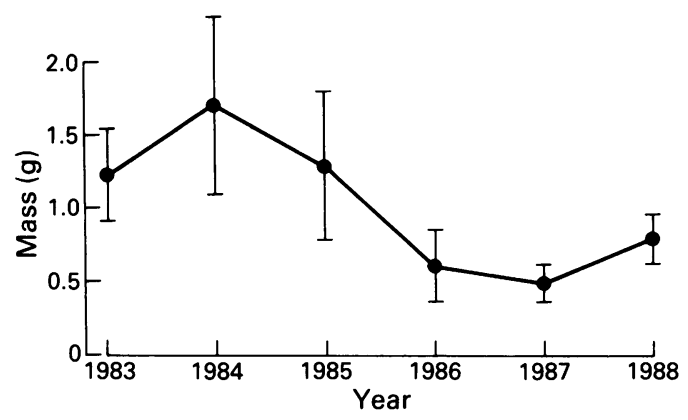

Figure 1 Mass of parathyroid adenomata resected per year of study (each point represents mean + s.d.).

explorations without any pre-operative imaging, ${ }^{15,16}$ and morbidity for the procedure remains low. In our series there were no deaths and no serious complications.

We conclude that patients with hypercalcaemia suspected of hyperparathyroidism should undergo radioimmunometric assay for the intact parathyroid hormone molecule. Patients with a raised intact parathyroid hormone level should be referred early for surgery with confidence in the diagnosis. The small size of adenomata now able to be detected biochemically has made thallium-technetium subtraction scanning unreliable as a preoperative localization technique.

\section{Acknowledgements}

We are grateful to Sir Arnold Elton for permission to report details of some of his patients in this study.

7. Percival, R.C., Blake, G.M., Urwin, G.H. et al. Assessment of thallium-pertechnetate subtraction scintigraphy in hyperparathyroidism. Br J Radiol 1985, 58: 131-135.

8. Nobin, A.P., Tennvall, J.G., Palmer, J.G. et al. Localisation of parathyroid glands by thallium-technetium subtraction scintigraphy. Acta Chir Scand 1987, 153: 581-586.

9. Wang, C.A. Anatomic basis of parathyroid surgery. Ann Surg 1976, 183: $271-275$.

10. Akerstrom, G., Malmaeus, J. \& Bergstrom, R. Surgical anatomy of human parathyroid glands. Surgery 1984, 95: $14-21$.

11. Nussbaum, S.R., Zahradnik, R.J., Lavigne, J.R. et al. Highly sensitive two-site immunoradiometric assay of parathyrin and its clinical utility in evaluating patients with hypercalcaemia. Clin Chem 1987, 33: 1364-1367.

12. Beahrs, O.H. Surgical management of hyperparathyroidism. Ann R Coll Surg Engl 1980, 62: 31-34.

13. Wheeler, M.H., Harrison, B.J., French, A.P. et al. Preliminary results of thallium 201 and technetium $99 \mathrm{~m}$ subtraction scanning of parathyroid glands. Surgery 1984, 96: $1078-1081$ 
14. Manni, A., Basarab, R.M., Plourde, P.V. et al. Thalliumtechnetium parathyroid scan - a useful noninvasive technique for localisation of abnormal parathyroid tissue. Arch Intern Med 1986, 146: 1077-1080.

15. Thompson, N.W., Eckhauser, F.E. \& Harness, J.K. The anatomy of primary hyperparathyroidism. Surgery 1982, 92: 814-822.
16. Satava, R.M., Beahrs, O.H. \& Scholz, D.A. Success rate of cervical exploration for hyperparathyroidism. Arch Surg 1975, 110: 625-628. 